\title{
Designing a Client and Family Empowerment Model to Promote Constructive Life Recovery Among Persons with Spinal Cord Injury: A Qualitative Study
}

\author{
Alireza Nikbakht Nasrabadi (iD ${ }^{1,2}$, Nooredin Mohammadi (iD ${ }^{3}$, Keyvan Davatgaran (iD ${ }^{4}$, Mirsaeed \\ Yekaninejad $^{5}$, Abbas Noroozi Javidan ${ }^{1}$ and Maryam Shabany ${ }^{1,{ }^{*}}$
}

${ }^{1}$ Brain and Spinal Cord Injury Research Center, Neuroscience Institute, Tehran University of Medical Sciences, Tehran, Iran

${ }^{2}$ Department of Medical Surgical Nursing, Nursing and Midwifery School, Tehran University of Medical Sciences, Tehran, Iran

${ }^{3}$ Department of Critical Care Nursing, Nursing and Midwifery School, Iran University of Medical Sciences, Tehran, Iran

${ }^{4}$ Iranian Research Center on Ageing, University of Social Welfare and Rehabilitation Science, Tehran, Iran

${ }^{5}$ Department of Epidemiology and Biostatistics, Public Health School, Tehran University of Medical Sciences, Tehran, Iran

"Corresponding author: Brain and Spinal Cord Injury Research Center, Neuroscience Institute, Tehran University of Medical Sciences, Tehran, Iran. Email: maryamshabanyi@yahoo.com

Received 2018 December 18; Revised 2019 January 10; Accepted 2019 February 13.

\begin{abstract}
Background: Spinal cord injury (SCI) causes financial, social, and psycho-emotional problems for both the person afflicted with SCI and the family. Family as an important source of care plays an important role in patients' rehabilitation and complication reduction. Objectives: The present study aimed at designing a client and family empowerment model for SCI patients.

Methods: This was a qualitative study with the grounded theory approach conducted in 2017. Unstructured interviews were used as the main method of data collection. Saturation was achieved with 43 participants, including people with SCI, family caregivers, and people involved in providing health care and rehabilitation services for people with SCI. Data analysis was performed on the basis of continuous comparative analysis of Strauss and Corbin (1998). In the second stage, the findings of the grounded theory study were used for designing the prescriptive model based on Walker and Avant (2005) three-step method.

Results: The main concern of people with SCI and their families was the loss of physical ability, financial and physical independence, and lack of constructive life. Ultimately, a "client and family empowerment model to promote constructive life recovery for individuals with SCI" was developed based on the findings of the grounded theory study. This model includes four main concepts: correction of environment, educational empowerment of the clients and families, modification of the method of providing rehabilitation services, and recovery of a constructive life.

Conclusions: There were several barriers to the client and family empowerment of people with SCI. In this study, a client and family empowerment model was developed to promote constructive life recovery and strategies were identified to remove the barriers. Hence, this model can help people with SCI to return their effective lives.
\end{abstract}

Keywords: Spinal Cord Injuries, Empowerment, Family, Qualitative

\section{Background}

Spinal cord injury (SCI) is one of the debilitating disorders of the central nervous system (1). In 2013, the World Health Organization reported that between 250000 and 500000 people were suffering from SCI worldwide (2). The prevalence of SCI is increasing in Tehran, the capital of Iran (3). People suffering from SCI are encountered with physical complications resulting from SCI, as well as various social and family challenges during their lifespan. Costs of caring for chronic conditions cause financial, social, and psycho-emotional problems for both the person with SCI and his family (4). Unfortunately, the number of families who have to care for patients with chronic conditions has been excessively increasing in the recent two decades (5).

Managing the conditions of chronic disease at home is a very complicated activity that is not feasible without the assistance of families (6). Helping the afflicted people and their families to have an active role in health care is something more important than providing care services, emphasizing the empowerment of the patient and his family. Measures taken in this regard should also be in line with developing cooperation among the patients, the families, and the health team including the nurses (7). Since 
therapeutic treatment and complication control are not solely sufficient after the disability and considering the determining role of nurses in rehabilitating the patients with psychological and physical disabilities, nurses could help the SCI patients increase their abilities in performing their daily activities (8).

On the other hand, family caregivers with the cooperation of the health team could help SCI patients increase their life quality and reduce the social, psychological, and economic problems (9). Therefore, if a suitable empowerment model is designed for SCI patients, the responsibility of controlling the patients will be performed more correctly (10).

Family-centered empowerment for SCI patients is a complicated process by nature that involves the interaction between members providing care for the patient and his family and includes different physical, psychological, social, cognitive, cultural, and economic dimensions (11). Therefore, the understanding of the empowerment process in these people starts from their hospitalization and continues until caring at home and returning to society. Nowadays, nurses are engaged in caring for and treating patients using different models and theories (12).

\section{Objectives}

Since there has been no comprehensive client and family empowerment model for Iranian SCI patients, this study aimed to design an empowerment model concerning the specific socio-cultural needs and conditions and based on the current realities of the Iranian society using the grounded theory.

\section{Methods}

\subsection{Study Design}

This study was performed using a qualitative method following a grounded theory approach. Client and family empowerment is a complicated and interactional social process that is influenced by different factors. Grounded theory is a qualitative research method used for investigating social processes in human interactions; thus, this approach was selected for the present study (13).

\subsection{Participants and Setting}

In sum, 43 persons participated in this work, 19 of whom were people with SCI, 13 were home caregivers, and 11 were health experts (including two neurosurgeons, a rehabilitation and empowerment director, a preventive medicine specialist, a sexual health specialist, a psychiatrist, occupational therapist, a psychologist, a physiotherapist, a nurse, and a social worker). The SCI Research Center, Tehran SCI Association, Jalaeipour Welfare Center was selected as the study setting in 2016 to 2017.

\subsection{Data Gathering and Interviews}

In-depth unstructured interviews were used as the main method of data collection. The duration of the interviews was between 25 and 120 minutes. In two cases, the interviews were done in two sessions in order to continue discussions.

At the beginning of the interviews, questions such as the following were asked: "As the family of an injured person, how do you care for him/her during the day?"; "How could your family help you?" and the health experts were asked, "How could you help empower the person with SCI?" The main criteria determining the number of interviews were the use of key informants, quality of data, emerging theory and levels, and achieving theoretical saturation.

\subsection{Data Analysis}

After reading and understanding the texts of all interviews, a suitable code was assigned to each phrase or paragraph. All the interviews were encoded by this method. After performing initial interviews, determining the fundamental codes, using the consecutive comparison method of data, and examining the similarities and differences within each interview or between the interviews, similar codes or those with similar meaning and concept were placed at the same level and thus, the primary or main levels were formed.

After forming the descriptive theory, the three-step synthesis method based on Walker and Avant's strategy for theory construction was applied to develop a prescriptive theory. In the first step after determining the key concepts for developing and processing the essential bases of the theory, a concept or a set of related concepts was specified for model development. In the second step, a text review was done in order to determine the factors depending on the main concepts and the nature of relations concerning the main selected paradigmatic concepts and related to the model's meta-paradigmatic concepts (14). Moreover, the data and the findings of the first step were applied as a relevant text and document. In the third step, concepts and statements were organized inside a relevant whole and the studied phenomenon was revealed by the findings of the above-mentioned two steps. The accuracy and durability of the data were ensured via reviewing the encoded interviews by the participants, the agreement of 
the members with the analyzed interviews, the categorization of similar codes and levels, diversity in the selection of participants, transcribing the interviews as soon as possible, and using the colleagues' comments (15). It should be noted that there was no limitation in the work. The ethical principles included obtaining a letter of introduction from the Research and Ethics Committees, Tehran University of Medical Sciences, receiving informed consent of participants for recording the interviews while maintaining the confidentiality and anonymity, and empowering them to exit the study during the research process. The study was approved by the Ethics Committee of Tehran University of Medical Sciences (No. IR.TUMS.REC.1394.1493).

\section{Results}

The demographic characteristics of the participants are presented in Table 1 . The data analysis resulted in extracting five main levels (disruption in the existential integrity of the individual, toward constructive life recovery, empowerment inhibitors, empowerment facilitators, and restarting) and 13 sub-levels (potentially harmful psychoemotional reactions, decline in social interactions and isolation, difficulty due to physical problems, family structure transformation, attempt to adapt with disability, trying to overcome physical disability, attempts for life management, lack of training for the family and the patient, defect in the provision of health services, inappropriate environment for utilizing rehabilitation services, painful feedback from the surrounding people, from chronic complications to dependence on the surrounding people, denial of disability, gradual return to the society and return to normal life).

The most evident concept that was revealed in the data from the time of affliction with SCI was "attempt for life recovery" since the only way for the injured people and their families is to return to the life they had before the SCI occurrence, which had been a normal, independent, and effective life. Health service providers also try to return people to their constructive lives via providing rehabilitation services. Accordingly, this concept was selected as a concept of the central level and the grounded theory of "toward constructive life" was formed. This descriptive theory is helpful in identifying the reactions and interactions existing in the real context of client and family empowerment and specifies that the participants try to recover their preinjury lives. However, this theory could not respond to the applied, clinical, and practical question that "how could this life be changed toward a constructive life in order to improve client and family empowerment and increase its efficiency?"
Therefore, in order to design a model, Walker and Avant's three-step method was applied. Considering the results obtained from the grounded theory in the first step, client and family empowerment among people with SCI has many obstacles, lacks desirable results in most cases, and is not based on the all-round needs of this group of people. The following question was also raised "how could client and family empowerment be improved in order to meet the needs related to the empowerment of people with SCI?" Therefore, considering the central level of the grounded theory in this survey that was toward a constructive life and considering client and family empowerment in order to advance constructive life recovery as the model pattern, the model was developed by using this concept and focusing on other concepts related to the central concept. The paradigmatic concepts of human, health, environment, and empowerment were also taken into account.

In the next step, the model's main factors and concepts were stated as follows: Considering the review of the texts and studying the issues concerning the model, i.e. "client and family empowerment in order to advance constructive life recover" and other constituting concepts, the conceptual framework of the human, environment, health, and empowerment was developed.

The concepts and main elements of the model were presented, as follows:

Human: As a biological, psychological, social, and spiritual being, the human always tends to be independent and constructive in his life. When a disruption occurs in one of the physical, mental-psychological, or social dimensions, humans will suffer from the disruption in their existential integrity in terms of losing their constructive lives. A client is a person who needs help and support in order to maintain his constructive life against the sense of threat.

Environment: It includes people involved in the client and family empowerment, social facilities, advanced equipment and technology for physical rehab, society's perception and awareness, care, psychological and physical conditions of the treatment and health system, remote health services, institutions supporting people with SCI, and cultural, economic and social contexts of the families and communities of the clients, which are in constant interaction with the people suffering SCI and influence each other.

Health: In the present model, health refers to the advancement of the constructive life recovery in people with SCI, dynamic attempt of the person in interaction and with the support of the family, society, and healthcare factors, and the desirable use of support sources for achieving the maximum capability and enjoyment form a constructive life.

Client and family empowerment: It means the efficacy 


\begin{tabular}{|c|c|c|c|}
\hline Variables & Persons with SCI (No.) & Family Caregivers (No.) & Health Professional (No.) \\
\hline Age range, $y$ & $24-63$ & $25-65$ & $35-53$ \\
\hline \multicolumn{4}{|l|}{ Sex } \\
\hline Women & 5 & 8 & 5 \\
\hline Men & 14 & 5 & 6 \\
\hline \multicolumn{4}{|l|}{ Education } \\
\hline Primary school & 1 & 5 & \\
\hline Secondary school & 11 & 8 & \\
\hline College & 7 & & 11 \\
\hline \multicolumn{4}{|l|}{ Marital status } \\
\hline Single & 7 & 1 & 1 \\
\hline Married & 9 & 11 & 10 \\
\hline Divorced & 3 & 1 & 0 \\
\hline \multicolumn{4}{|l|}{ Job status } \\
\hline Employed & 5 & 10 & 11 \\
\hline Unemployed & 14 & 3 & 0 \\
\hline \multicolumn{4}{|l|}{ Type of SCI } \\
\hline Complete & 9 & & \\
\hline Incomplete & 10 & & \\
\hline \multicolumn{4}{|l|}{ Cause of injury } \\
\hline Car accident & 16 & & \\
\hline Falling & 2 & & \\
\hline Hit of the bullet & 1 & & \\
\hline Length of time since SCI, mo & $12-360$ & & \\
\hline \multicolumn{4}{|l|}{ Relationship with the patient } \\
\hline Mother & & 6 & \\
\hline Wife & & 3 & \\
\hline Father & & 2 & \\
\hline Daughter & & 1 & \\
\hline Brother & & 1 & \\
\hline \multicolumn{4}{|l|}{ Level of injury } \\
\hline $\mathrm{C} 1-\mathrm{C} 7$ & 5 & & \\
\hline $\mathrm{T} 1-\mathrm{T} 12$ & 12 & & \\
\hline L1 - L5 & 2 & & \\
\hline
\end{tabular}

of the family role in different psychological, physical, motivational, and informative dimensions for providing better care for their patients.

Multidisciplinary team empowerment: For people with SCI, it includes a group of specialists who perform a set of supportive and healthcare activities together for a specific and valuable objective, the result of which is the empowerment of injured and disabled individuals to returning them to the constructive life. The rehabilitation team includes a rehabilitation physician, a neurological specialist, a physiotherapist, an occupational therapist, a social worker, a rehabilitation nurse, a rehabilitation psychologist, a professional consultant, and a nutritionist.

Constructive life: It is accomplished via acceptance and compatibility, overcoming physical disability, and managing the life for balance establishment. Constructive life is in fact a life accompanied by the sense of being indepen- dent, active, and effective in the family life and society, having social generation (i.e. performing professional and social responsibilities and having a job and income) and family generation (managing life, compatible with new life, and doing family responsibilities and roles), maintaining social interactions, and having positive effects on the lives of others.

Furthermore, the current model proposed empowering the persons with SCI and their families through developing knowledge, motivation, and awareness, as well as strengthening self-care and self-efficacy by employing nursing interventions.

The environmental modification should be such that it could have the maximum usability for all. Designing the access system and modifying the supportive environment were the other proposed interventions in the present model. Finally, improving the method of rehabilitation 
service provision was among other suggestions including team working, evidence-based practice, and empowerment programs for nurses and other members of the care team.

\section{Discussion}

In this study, an applied model was presented to simplify a theory and visualize the concepts and conceptual relations stipulated in the theory extracted from the grounded theory research as far as possible and also provide practical solutions for applying the theory in practice. The client and family empowerment model was processed in order to advance the constructive life recovery based on Walker and Avant's three-step method.

Empowering the patient with SCI, as well as his family, is proposed as an intervention via developing knowledge, motivation, and awareness, as well as strengthening selfcare and self-efficacy in the person with SCI by employing nursing interventions such as justifying SCI patients and their families in terms of strengthening their remaining capabilities, sharing them with care decisions, strengthening problem-solving, and decision-making skills, as well as promoting communications and self-awareness in the studied model. Tsey et al. results showed that localized empowerment concerning the people's needs could help the emotional wellbeing of the society and family and result in the recovery of health norms in the family and society (16). In another work by Houlihan et al. on people with traumatic SCI, which lasted more than one year, it was reported that empowerment is very important for people with SCI and could prevent the secondary complications of SCI, improve self-confidence and sense of support, and promote more communication with supportive sources (17).

The results of Dunst et al. study demonstrated that empowerment with the family cooperation, specifically in chronic conditions, could increase awareness and knowledge, perceived control over life, self-efficacy, and satisfaction of home caregivers (18).

Modifying the supportive environment and designing the access system were the other proposed interventions in the present study. The environmental modification should be such that it could have maximum usability for all (19). Rosenberg et al. found in their work that the modification of living environments of old and disabled people who were using aids such as walkers and wheelchairs was essential for maintaining their physical health and independence (20).

Moreover, this study proposed to improve the method of presenting rehabilitation services. Rathose et al. found in their work in Pakistan that only had a minority of the patients access to rehabilitative care such as physiotherapy during the first weeks after their SCI, which was provided without the cooperation and consulting of a rehabilitation physician. They concluded that there is a need for a comprehensive rehabilitation plan among people with SCI (21). This finding was similar to the one in the current study. Peters et al. and Jacobs et al. have reported in their studies on identifying the obstacles of access to health services in lowincome Asian countries that the dimensions of obstacles for access to health services include geographical access, access to health services and financial capability, and acceptability (characteristics of health service providers and users' expectations). They stated that overcoming such obstacles could be effective for the general improvement in providing health services (22).

Having a constructive life among people with SCI is another recommendation in the present work. The results of the study by Song showed that family support, access to information, perceived stress, and social obstacles were considerably related to active return to the society, which is one of the factors for running a constructive life. These findings revealed the outcomes of intervention development at different levels including the family and society and the personal coping strategies for promoting the return to the active and effective life among people with SCI (23).

In our model, the modification of the environment and its comprehensiveness were mentioned in order for better access to facilities and having minimum obstacles so as to be used for all. A social rehabilitation model was developed by researchers and activists in the area of disability in Australian, England, the USA, and other developed countries, which was applicable to all disabled people. In this model, environment's enrichment was proposed for fair access of patients to welfare facilities in the society as an example for providing sufficient equipment and facilities in the social environment of people with SCI in order for them to have a natural life just like a healthy person and use environmental facilities such as welfare and recreational facilities (24).

Improving the method of rehabilitation service provision was among other suggestions of this model. In the expanded chronic care model presented by Barr et al., strategies for improving the trend of care services and increasing care quality were proposed that included changing the care presentation to a team activity, as well as cooperation and coordination of caregivers and therapist in the health system, that could help promote empowerment quality of people with the cooperation of the family (25).

In this model, constructive life recovery was also referred to. In their rehabilitation model, Ghaffari et al. mentioned the return to a productive and independent life of the patients with multiple sclerosis as the rehabilitation care target (26). 


\subsection{Conclusions}

The client and family empowerment model to promote constructive life recovery in individuals with SCI was presented in the current study. It explained strategies to remove barriers, including improvement of the supporting environment by creating a barrier-free and accessible environment, empowering SCI patients and their families by creating knowledge, motivation, and awareness, strengthening self-care and self-efficacy in SCI patients by applying nursing interventions, and improving the provision of rehabilitation services with self-care support, educational interventions, teamwork, and participatory care provision. Examining the existing models determined that there has been no comprehensive client and family empowerment model for Iranian SCI people relative to their specific sociocultural needs and conditions and based on the realities of Iranian society. Therefore, it can help recover the constructive lives of patients with SCI.

\section{Footnotes}

Authors' Contribution: Alireza Nikbakht Nasrabadi was responsible for suggesting topic, helping to acquiring data, drafting and revising the article. Maryam Shabany responsible for performing and typing interviews, analyzing and interpreting the interviews, writing the manuscript. Nooredin Mohammadi and Keyvan Davatgaran drafting and revising the article. Mirsaeed Yekaninejad and Abbas Noroozi Javidan helping to analyzing quantitative data and drafting the article. Nooredin Mohammadi and Alireza Nikbakht Nasrabadi assessed the accuracy of analysis and extracted themes, and their perspectives were applied.

Conflict of Interests: It is not declared by the authors.

Ethical Approval: IR.TUMS.REC.1394.1493.

Funding/Support: There is no funding/support.

\section{References}

1. Glass C. Treatment and rehabilitation following spinal cord injury. Pers Inj Law Med Rev.1993;1:51-70.

2. Essential medicines and health products. Geneva: Wold Health Organization,; 2013. Available from: http://www.who.int/medicines/ news/2018/presentation_SanaHafeez-WHO-Champion-assistiveproducts/en/.

3. Rahimi-Movaghar V, Saadat S, Rasouli MR, Ganji S, Ghahramani M, Zarei MR, et al. Prevalence of spinal cord injury in Tehran, Iran.J Spinal Cord Med. 2009;32(4):428-31. doi: 10.1080/10790268.2009.11754572. [PubMed: 19777865]. [PubMed Central: PMC2830683].

4. Tulsky DS, Kisala PA, Victorson D, Tate D, Heinemann AW, Amtmann D, et al. Developing a contemporary patient-reported outcomes measure for spinal cord injury. Arch Phys Med Rehabil. 2011;92(10 Suppl):S44-51. doi: 10.1016/j.apmr.2011.04.024. [PubMed: 21958922]. [PubMed Central: PMC6309317].
5. Schulz R, Sherwood PR. Physical and mental health effects of family caregiving. Am J Nurs. 2008;108(9 Suppl):23-7. quiz 27. doi 10.1097/01.NAJ.0000336406.45248.4c. [PubMed: 18797217]. [PubMed Central: PMC2791523].

6. Reinhard SC, Levine C, Samis S. Home alone: Family caregivers providing complex chronic care. Washington, DC: AARP Public Policy Institute; 2012.

7. Speer PW, Jackson CB, Peterson NA. The relationship between social cohesion and empowerment: support and new implications for theory. Health Educ Behav. 2001;28(6):716-32. doi: 10.1177/109019810102800605. [PubMed: 11720274].

8. Bailey J, Dijkers MP, Gassaway J, Thomas J, Lingefelt P, Kreider SE, et al. Relationship of nursing education and care management inpatient rehabilitation interventions and patient characteristics to outcomes following spinal cord injury: The SCIRehab project. J Spinal Cord Med. 2012;35(6):593-610. doi: 10.1179/2045772312Y.0000000067. [PubMed: 23318039]. [PubMed Central: PMC3522899].

9. Ghasemi M, Alhani F, Gholami M, Daneshpazhooh M. [The effect of family-centered empowerment model on quality of life of female patients with pemphigus vulgaris referred to Razi hospital]. Iran J Nurse Res. 2018;13(3):1-10. Persian. doi: 10.21859/ijnr-13031.

10. Aujoulat I, Marcolongo R, Bonadiman L, Deccache A. Reconsidering patient empowerment in chronic illness: A critique of models of self-efficacy and bodily control. Soc Sci Med. 2008;66(5):1228-39. doi: 10.1016/j.socscimed.2007.11.034. [PubMed: 18155338].

11. Alhani F, Niknami S, Kimiagar M, Kazemnezhad A, Heidarni A. [Design and evaluation of the family-oriented prevention of iron deficiency Anemia]. Tehran Tarbiat Modares University. 2003;8:283-9. Persian.

12. Mahdizadeh M, Heydari A, Karimi Moonaghi H. Clinical interdisciplinary collaboration models and frameworks from similarities to differences: A systematic review. Glob J Health Sci. 2015;7(6):170-80. doi: 10.5539/gihs.v7n6p170. [PubMed: 26153158]. [PubMed Central: PMC4803863].

13. Lewis S. Qualitative inquiry and research design: Choosing among five approaches. Health Promot Pract. 2015;16(4):473-5 doi: $10.1177 / 1524839915580941$.

14. Timmermans S, Tavory I. Theory construction in qualitative research: From grounded theory to abductive analysis. Socio Theor. 2012;30(3):167-86. doi: 10.1177/0735275112457914.

15. Rolfe G. Validity, trustworthiness and rigour: quality and the idea of qualitative research. J Adv Nurs. 2006;53(3):304-10. doi: 10.1111/j.13652648.2006.03727.x. [PubMed: 16441535].

16. Tsey K, Wilson A, Haswell-Elkins M, Whiteside M, McCalman J, Cadet-James Y, et al. Empowerment-based research methods: A 10-year approach to enhancing Indigenous social and emotional wellbeing. Australas Psychiatry. 2007;15 Suppl 1:S34-8. doi: 10.1080/10398560701701163. [PubMed: 18027133].

17. Houlihan BV, Everhart-Skeels S, Gutnick D, Pernigotti D, Zazula J, Brody M, et al. Empowering adults with chronic spinal cord injury to prevent secondary conditions. Arch Phys Med Rehabil. 2016;97(10):1687-1695 e5. doi: 10.1016/j.apmr.2016.04.005. [PubMed: 27143581].

18. Dunst CJ, Trivette CM, Hamby DW. Meta-analysis of family-centered helpgiving practices research. Ment Retard Dev Disabil Res Rev. 2007;13(4):370-8. doi: 10.1002/mrdd.20176. [PubMed: 17979208].

19. Stone PW, Hughes R, Dailey M. Creating a safe and high-quality health care environment. In: Hughes RG, editor. Patient safety and quality: An evidence-based handbook for nurses. Rockville (MD); 2008. eng.

20. Rosenberg DE, Huang DL, Simonovich SD, Belza B. Outdoor built environment barriers and facilitators to activity among midlife and older adults with mobility disabilities. Gerontologist. 2013;53(2):26879. doi: 10.1093/geront/gns119. [PubMed: 23010096]. [PubMed Central: PMC3605937].

21. Rathore MF, Hanif S, Farooq F, Ahmad N, Mansoor SN. Traumatic spinal cord injuries at a tertiary care rehabilitation institute in Pakistan. J Pak Med Assoc. 2008;58(2):53-7. [PubMed: 18333519]. 
22. Jacobs B, Ir P, Bigdeli M, Annear PL, Van Damme W. Addressing access barriers to health services: an analytical framework for selecting appropriate interventions in low-income Asian countries. Health Policy Plan. 2012;27(4):288-300. doi: 10.1093/heapol/czr038. [PubMed: 21565939].

23. Song HY. Modeling social reintegration in persons with spinal cord injury. Disabil Rehabil. 2005;27(3):131-41. doi: 10.1080/09638280400007372. [PubMed:15823995].

24. Oliver M. The social model of disability: thirty years on. Disabil Soc.
2013;28(7):1024-6. doi: 10.1080/09687599.2013.818773.

25. Barr VJ, Robinson S, Marin-Link B, Underhill L, Dotts A, Ravensdale D, et al. The expanded chronic care model: An integration of concepts and strategies from population health promotion and the chronic care model. Hosp Q. 2003;7(1):73-82. [PubMed: 14674182].

26. Ghaffari S, Mohammadi E, Nouroozi K. [Designing a rehabilitation care model for patients with multiple sclerosis]. University of Rehabilitation Sciences and Social Welfare; 2013.345 p. Persian. 